\title{
Characteristic of Disasters Management in Australia and Its Enlightenment
}

\author{
Yue Gao* \\ College of Geography Science, Chongqing Normal University, Chongqing 400047, China
}

\begin{abstract}
Australia has established an excellent national system of disasters management. Disasters management in Australia is characterized by sophisticated ideas of disasters management, strong legislation, solid technical instructions and normal operation, extensive involvements of volunteers and mode of risk management. Based on the above introduction, the author proposes the following points in order to imp rove disasters management in China: strengthening constructions on legislation and organization; enhancing researches on natural hazards and emergency management; using the risk management app roach; concerning with prevention and preparedness; paying more attention to community.
\end{abstract}

\section{KEYWORDS}

Disaster management

Characteristics

Australia

\section{Introduction}

Australian common natural disasters include: floods, storms, tropical storms, forest fires and other types, earthquakes and landslides in some areas occasionally occur. In the past few decades, natural disasters, socio-economic development in Australia caused serious losses to people's lives and property but also brings a certain threat. According to the Australian Bureau of Transportation economic reports, from 1969-1999, the natural disasters caused economic losses to Australia from 1 million Australian dollars rose to 37.8 billion Australian dollars, with an average annual loss of 11.4 billion Australian dollars disasters [1].

In fact, as a continent, Australia suffered natural disasters is relatively less severe, extreme natural disasters (such as storms, tornadoes, volcanic eruptions, earthquake, landslides, etc.) almost did not appear in Australia, and natural disasters the number or frequency is not too high. According to information the Australian Transport Economic Bureau, the 33 years period from 1967-1999, there were natural disasters Australia 265 times, an average of eight times per year of natural disasters. More fortunately, not many

Copyright () 2014 Yue Gao

doi: $10.18686 /$ utc.vli1.5

Received: February 19, 2014; Accepted: April 25, 2014; Published online: June 29, 2014

This is an open-access article distributed under the terms of the Creative Commons Attribution Unported License (http://creativecommons.org/ licenses/by-nc/4.0/), which permits unrestricted use, distribution, and reproduction in any medium, provided the original work is properly cited.

${ }^{\star}$ Corresponding author: College of Geography Science, Chongqing Normal University, Chongqing 400047, China. E-mail: gaoyy1978@163.com deaths caused by disasters, the total number of approximately 560 people, including one death caused by disasters in 1974 is the largest Darwin Tracy typhoon, the typhoon killed 50 people [1]. The Center for American Studies of the University of Colorado natural disaster data showed that 19-year period from 1975-1994, the number of deaths caused by natural disasters in the United States personnel over 24,000 people, with an average annual disaster loss amounted to $\$ 26$ billion [2]. China is more severe natural disaster losses, normal year, and the disaster affected population of about 200 million people affected by the country in which the death tolls of thousands of people, to be relocated more than 300 million people. According to the National Disaster Reduction Center data show that, four years 2001-2004, death tolls of 9,431 people, 7,065 one hundred million yuan of direct economic losses [3].

Australia's natural disasters reason less severe damage and casualties are manifold: one reason is sparsely populated; ancient and stable geological structure and relatively flat topography is characterized by aspects of natural causes; Australia effective disaster management is another important reason.

\section{Australia's disaster management system}

Australia's national disaster management system consists of three part National Emergency Management Committee, the federal government and state emergency management organization of emergency or disaster management organizations [4]. Clear division of labor at all levels and functions, coordination and efficient operation.

Australia's national system of disaster management is the 
federal government, state or territory government partnership, between the local government and communitybased [5]. As a federal state, according to the provisions of the Federal Constitution, the state government is responsible for protecting life and property of citizens under the jurisdiction of local governments responsible for disaster response and implementation of specific organizations, and the federal government is responsible for external representation of Australian overseas disaster emergency, internal behalf of the State to give the state government to help in the deployment and coordination, financial assistance, emergency technical standards and training aspects of national resources. Disaster management system in Australia, the state government on disaster management and emergency planning have the primary responsibility, they enacted relevant legislation and policies, through the implementation of local government to reflect its management role, and local governments, directly organize disaster contingency plans and embodiment.

Within the federal government, the Ministry of Justice is responsible for the current disaster and emergency services management, Emergency Management Australia is the federal emergency management agency affairs. Formerly Emergency Management Australia is a natural disaster organization established in February 1974 is part of the Federal Ministry of Defence (Natural Disasters Organization, $\mathrm{NDO}$ ), then NDO has coordinated federal and material assistance to help states and state civil defense functions when disaster management capabilities construction. January 1993, NDO was renamed the Emergency Management Australia (Emergency Management Australia, EMA), the mandate of the institution, though still natural disaster management is an important task, but also adds other emergency (such as artificial sudden technological accidents, rescue, etc.) task. November 2001, EMA separated from the Ministry of Defence, was placed under the leadership of the Federal Ministry of Justice [6]. Emergency Management Australia functions are: (1) Strengthen the national emergency management capability; (2) Reduce disaster vulnerability of communities; (3) Improve the ability of local emergency management and awareness.

\section{Australia disaster management features 3.1. There are more advanced disaster management concepts}

A successful experience of Australia is to set up a disaster guide disaster planning and management concepts and principles [6], namely "four concepts and the six principles". These concepts and principles was the National Natural Disaster Organization (NDO, 1989) summarizing the development of Australia's past practice and disaster management concepts based on the up [7]. Although the concept of the establishment of the NDO and the national provisions in principle not mandatory, but as guidance, it is widely accepted by state governments. Its critical think- ing and basic elements have been incorporated into the relevant legal provisions in the states, which has a mandatory feature.

Four concepts, one all-hazards approach that is no matter what kind of disaster or emergency, disaster emergency management task facing are similar, although the measures and methods to deal with specific hazards are different. But logically speaking, the same can be applied to emergency management arrangements for emergency treatment of various disasters. Second, the integrated approach, which should be the prevention of disaster emergency management (prevention), preparedness (preparedness), response (response) and recovery (recovery) four basic elements (PPRR). Third, the method of all agencies, namely disaster prevention and mitigation arrangement is based on the positive "partnership" with all relevant agencies, levels of government, NGO and communities, many different organizations in the implementation of a "PPRR" or more management elements plays an important role, they represent some of the planning and management structure. Four is fully prepared communities that PPRR in disaster management, the focus of the community is the most basic, community disaster that may occur should be fully prepared.

In order to ensure the smooth conduct of disaster management, Emergency Management Australia has also established a set of six principles of disaster management, these principles are: (1) The appropriate organizations (disaster management arrangements must have an operating mechanism support, establish clear responsibility PPRR The mechanism); (2) Command and control (before the disaster, must clearly specify the disaster control and command of the department in the form of legal or contingency planning); (3) Support the coordination (in disaster planning, you must specify support the deployment mechanism and responsibilities of disaster resources); (4) Information management (developed communications network); (5) The timely start to start (emergency plan can not affect whether the government declared a state of disaster emergency, contingency plans best appointed by the superior Disaster emergency officials start); (6) Effective disaster contingency plans.

\subsection{Sufficient legal basis}

Commonwealth of Australia Constitution clearly stipulates: "State or territory has the primary responsibility to protect their lives and property of citizens, and the federal government have a responsibility to support and help states develop their disaster emergency management capability". Under the provisions of the Constitution, the federal government developed a national emergency management policy, the establishment of relevant institutions to support the development and construction of the state emergency management through financial and technical means.

States through their legislative power to establish an independent organization system and the implementation of 
management responsibility for the state of disaster emergency management. In general, state regulation will clearly specify the structure of disaster management organizations. What do they do? How do they work? Provided under the Act to take responsibility for the conditions of action immunity [8], but the division of responsibilities and powers of the state disaster management organization and planning and management, there are some differences. For example, in New South Wales, power to contingency planning would be assigned to the local government, in New South Wales "State Emergency and Rescue Management Act 1989", in addition to the establishment of state-level emergency management organizations and programs, the provisions of each place The Government should establish a local emergency management committee, local emergency management committee responsible for preparing disaster within local range of prevention, preparedness, response and disaster recovery planning.

\subsection{Technical guidance efforts and management practices}

EMA as a specialized agency of the federal government emergency management, full implementation of the mission entrusted by the Constitution: the support and guidance of state emergency management capacity building, to help create a sense of disaster, there are well-prepared society. For this reason, EMA put a lot of energy to carry out research Disaster Management, organized a group of scholars and experienced disaster managers prepared a series of handbooks Emergency Management Australia. As early as 1989, he published a set of emergency Technical Reference Manual. Then we continue to enrich the contents of the revised and expanded series of manuals. Currently, EMA has issued 36 written technical manuals and guides, are prepared eight technical manuals and guides, plan to write a new manual.

EMA's emergency manual is divided into five series. The first series is the basic principle, which relates to the concept of disaster emergency management, principles, arrangements, vocabulary and terminology; the second series of emergency management approach, involving the implementation of disaster risk management, mitigation and emergency planning programs; third series an emergency management practices, involving disaster relief, disaster recovery, disaster medical and psychological services, community contingency planning, community services, community development; the fourth series is technical emergency services, covering emergency response organization and leadership, operations management, search rescue, communications, Maps, etc.; fifth series of training management. These rich and comprehensive technical manual, both theoretical, and practical, both methods have operational skills targeted. These manuals will be distributed to the national state emergency management agencies, community organizations, government agencies and schools, the states have a strong disaster management guidance, but also to raise public awareness of disaster is important.

EMA also through the organization of emergency management training courses, provide emergency management information consulting services and direct participation in local disaster relief operations and other means to guide state disaster emergency management.

In addition, to make disaster emergency management standardization, the state has promulgated the Australian risk management standards [9], according to the quality management standard to define and implement the process of disaster management organizations.

\subsection{Featuring a wide range of volunteer community involvement}

In many countries, in disaster emergency response to the first line it is the paramilitaries, militias and even armies. But in Australia, when disaster strikes, many organizations and people involved in disaster operations. In each state or territory involved in disaster for the police, regular fire brigade, first aid teams, more forms of disaster volunteer organizations such as the State Emergency Service Center, forest fire prevention team, St. John's first aid team, surf lifesaving club, rescue service station. In addition, there are many people are not members of relief organizations, will actively participate in disaster operations and become temporary volunteer disaster [10].

In Australia, volunteer emergency response organization has roughly 500,000 trained volunteers, they accounted for $2.5 \%$ of Australia's population, and the police, fire brigade and other government disaster personnel only 64,000 people [11]. So, in Australia, it is a disaster volunteer force, they come from the community, to serve the community. A large number of volunteers involved in disaster mitigation and preparedness activities in the community, greatly strengthened the impact of volunteers in Australian society and values.

State Emergency Service Center (State Emergency Service, referred SES) is one of many disaster volunteer organizations more common form. SES is to help communities deal with flood and storm emergency and rescue volunteer organizations. In New South Wales, there are 230 SES station, located in the community, volunteers, members of the 10,000 people, there are regular staff of 60 people, the organization and maintenance of SES's daily operations and emergency services. State Emergency Service Center mission is to prepare the community flood plan to help weather bureau official release of flooding and storm alerts, evacuation and rescue stranded residents and their property, disaster public education.

To volunteer as the main team is the core of community disaster preparedness construction composition, which fully reflects the concept of disaster management in Australia: well-prepared community, in fact the Australian top 
disaster planners and managers regard the community as a national disaster. The basic strength. Volunteers are not amateurs, they must participate in training, and to achieve professional standards, must be able to skillfully operate a variety of complex disaster equipment. Volunteer organizations to conduct a series of training volunteers (including water boating safety first aid, disaster property protection, etc.).

\subsection{Risk management as the basic way of disaster management}

Australia in the 1990s is widely accepted on disaster risk awareness that the struggle with the disaster, people cannot just focus on the disaster itself, but also concerned about the social and environmental. Disaster risk is a result of environmental disasters and social vulnerability of the role. In fact, disaster is inevitable. Therefore, learn how to reduce the risk, how to survive in the disaster risk management but the fundamental problem [12], for which they will introduce risk management mechanisms to natural disasters management.

To promote and standardize disaster risk management, Australia early in 1995 promulgated the national risk management standard, which established risk identification, analysis, evaluation of the basic framework, processing and monitoring, Emergency Management Australia immediately prepared in accordance with this standard, the organization the "Emergency Risk Management Application Guide" [13]. Thus, risk management has become Australia's implementation of disaster management is a basic model. Emergency disaster risk management is the process of forming a series of measures to address community risks and enhance community safety and sustainable development of. Emergency disaster risk management uses to establish the background, level of risk, risk analysis, risk assessment, risk management and other steps to establish the risk level of the community, to find measures to deal with the risk.

\section{Discussion}

(1) Australia through the promotion and implementation of the four concepts of disaster management and the six principles of unity and improve the managers of scientific ideas and technical methods of disaster management, to improve disaster management, disaster prevention and reduction work has laid a solid theoretical foundation and guide to action. 4 The concept is highly concentrated Australian scientists disasters and disaster management law to study the nature of the disaster, it is the basic concept of disaster management in Australia; six principles are mainly successful in Australia nearly 20 years of experience in disaster management. In China, human and natural disasters has quite a long history of struggle and has accumulated a lot of experience, summed up the prevention, disaster prevention, disaster and relief combined; mainly to the mass- es, the masses, the collective and state power combination; the production-based self-help, self-help production, help each other and support the national relief combining "mitigation strategic thinking". However, from a scientific management level, for disaster awareness was not clear enough, it has not established the basic theory of disaster management and operational guidance, standardized disaster management guide to action. The need to strengthen disaster law and disaster management research, to establish a conceptual framework for national disaster management. This conceptual framework has many benefits, it helps to form a unified thinking, establish procedures to ensure that standardized methods, improve management efficiency, which is the basis for scientific management of disasters.

(2) The laws and regulations are essential to protect modern social management, organization is the basic means to achieve modern social management. Disaster Management is also inseparable from the support and protection of the laws and regulations of the organization. There are laws and regulations as a basis for the implementation of disaster management have social security, a specialized organization, management tasks can be specifically implemented.

Australia's disaster legislation and regulations very clearly establish the legal status of disaster management, the provisions of the people in mitigation actions should be how to do it, and people with certain constraints coercion to do so, and this is the important experience of disaster management in Australia and feature. To give full play to the important role of law in disaster management, disaster reduction must improve the legal system, improve national and local disaster mitigation planning, policy research development and strengthening disaster management and mitigation policies. It should be said, the development of relevant laws in our country to disaster reduction, or more important, also in some areas of natural disasters developed a number of relevant laws and regulations. There are some matters of government departments responsible for disaster management [14]. But from the perspective of the national disaster prevention and mitigation, it is still a lack of laws and regulations or comprehensive disaster prevention and mitigation of disaster management, such as a comprehensive basis of "mitigation of the Basic Law" and "Natural Disaster Relief Law", which can be specified Basic Disaster various Chinese the nature of mitigation, relations policies, the basic concepts and principles, the main mode, targets, planning, implementation and management, organization, and the use of economic resources, mitigation departments, as well as all levels of government, organizations, groups in disaster reduction process responsibilities, powers and obligations. The implementation of the Basic Law is a national disaster reduction and mitigation of the basic premise of the law, but also realize the importance of disaster management science foundation and an important measure. 
Unified integrated disaster management system implemented in Australia is Australia's high mitigation effectiveness, efficiency good important reasons. Emergency Management Australia is based on the Federal Constitution established co-ordination, exercise the functions of the national disaster management affairs official body, its powerful organizational disaster management leadership and technical guidance has played a huge role in the Australian National Disaster Reduction. The current management system of disaster reduction is "sub-sector management" or "compartmentalization management" on the specialized natural disaster mitigation management highly targeted, but the lack of a strong unified permanent disaster emergency management agency, coordinated disaster mitigation organizations and the deployment of resources and so have some difficulties. China is a country with frequent natural disasters [15] countries. Natural disaster management, related to the life and property safety of the people, should be an important part of the government's social management and public services, strengthening disaster management, to establish a unified national and local disaster mitigation permanent regulatory agencies is necessary.

(3) Disaster management is related to disaster prevention, mitigation aspects of systems engineering, content and more complex tasks, from the perspective of disaster prevention and mitigation, these tasks can be divided into pre-disaster prevention and preparedness, and emergency response and post-disaster outbreak of Reconstruction of four parts. From the current practice of disaster management point of view, but also strengthen the prevention and preparedness before the disaster, so be prepared, in fact, pre-disaster prevention and preparedness is the most effective measures to mitigate the consequences of disasters.

(4) The local community should be the basic starting point for disaster management. Community directly facing the disaster, is a potential victim of the disaster, is also effective disaster management beneficiaries. From now, the self-help communities are the most important and most effective mitigation measures. Public awareness of community disaster, community emergency response programs and measures, appropriate emergency response agencies and community organizations is the basic content disaster management and construction. Improve community disaster prevention and mitigation, and disaster prevention and mitigation target the whole of society can be achieved.

In Australia, the emergency service stations widely distributed in the community, they are responsible for the development of community emergency plan, organize volunteers to help themselves disaster for public disaster literacy. Volunteer-based organization has a special meaning in the form of disaster in disaster reduction work. First, he raised and trained a community of civic awareness and responsibility, which brings more security for the community; secondly, he raised a rapid emergency response, reducing the extent of the damage of disasters on communities; then there he is Social saving a lot of money. More importantly, a volunteer organization through their actions, at the local community to cultivate a spirit of solidarity and self-help, this spirit is the basis for building a more vibrant society.

In China, the national and local governments for disaster issue is quite important, but in the national disaster strategy and planning into the grassroots community and individual codes of conduct and practical action inadequate. There are many reasons, but not enough to focus on the local community is the primary reason for Disaster Reduction. Therefore, the central disaster management down, strengthen the construction of disaster prevention and mitigation of local communities, should be an important measure to improve the management efficiency of the current disaster.

\section{References}

1. Bureau of Transport Economics. (2001). Economic Costs of Natural Disasters in Australia:Report 103. Canberra:Department of Transport and Regional Service, 180.

2. Dennis, S. M. (1999). Disasters by Design. Washington D.C.:Joseph Henry Press, 82-85.

3. Disaster Information section 2001-2004 National Disaster .http:. //www.ndrcc.gov.cn [EB / OL], 2005203218/2005205206.

4. Emergency Management Australia (EMA). (2000). Australian Emergency Management Arrangements (6thEdition). Canberra:Common wealth of Australia,.

5. Chapmand. (1999). Natural Hazards. Melbourne:Oxford University Press, 146.

6. Emma, M. A. (2003). Hazards Disasters, You're Your Community (Sixth Edition). Canberr: Common wealth of Australia, 91.

7. Natural Disasters Organization (NDO). (1989). Common wealth Counter disaster Concepts and Principles. Canberra:Common wealth of Australia, 116.

8. Handmerjw, P. (1986). Flood Warnings and Legal Liability, the George River Floods. Canberra:CRES, 371-373.

9. NDO. (1995). Standards Australia Risk Management. AS/ NZS43602.

10. NDO. (1992). Hazards, Disasters \& Survival. Canberra: Common wealth of Australia.

11. Brittonn. (1990). Disaster Volunteers, In the Newsletter of International Hazards Enfield, Flood Hazard Research Center, 59.

12. Grahamaz. (1999). Disaster Risk Management. Queensland: Department of Emergency Service, Queens Land Government, 192-193.

13. Elisa, S. (1998). Emergency Risk Management Application Guide. Canberra: Common wealth of Australia, 63-64.

14. Yao, Q. L., Liu, B., \& Lu, Z. H. (1998). Disaster Management. Changsha: Hunan People's Publishing House, 233235.

15. Guo, Y., \& Lin, X. S. (2001). The complexity analysis of geological disaster system. Chongqing Normal University (Natural Science), 18(4), 126. 